\title{
Model Komunikasi Corporate Sosial Responsibility (CSR) PT. Telkom dalam Pemberdayaan Ekonomi Masyarakat Pasca Gempa
}

\author{
Puji Lestari $^{1}$, Eny Endah Pujiastuti², Ida Wiendijarti ${ }^{3}$ \\ ${ }^{1,3}$ Program Studi Ilmu Komunikasi, ${ }^{2}$ Program Studi Administrasi Bisnis \\ 1,2,3Fakultas Ilmu Sosial dan Ilmu Politik, Universitas Pembangunan Nasional "Veteran" Yogyakarta \\ Jl. Babarsari No. 2 Tambakbayan Yogyakarta, 55281, Indonesia \\ Email: puji.lestari@upnyk.ac.id
}

\begin{abstract}
The community complained that their business was threatened with failure which caused the economy to be disrupted after the earthquake. The purpose of this study was to find a communication model for PT. Telkom's Corporate Social Responsibility (CSR) to improve the economic empowerment of earthquake victims in UKM in Sleman Yogyakarta. This research method uses a subjective approach to qualitative data. Data collection was carried out by interview and FGD (Focus Group Discussion). The subjects of this study were small and medium entrepreneurs (UKM) who were victims of the earthquake in Sleman Yogyakarta and the CSR team from PT. Telkom Kandatel Yogyakarta. Data analysis was carried out qualitatively through data reduction, data presentation, and concluding. The results of this study found PT. Telkom's Corporate Social Responsibility (CSR) communication model to improve the economic empowerment of earthquake victims in UKM in Sleman Yogyakarta. The contribution of this research is in the form of recommendations to government and private companies to apply the Corporate Social Responsibility (CSR) communication model to increase the economic empowerment of the surrounding community. Keywords: Communication Model of PT. Telkom's Corporate Social Responsibility (CSR); Economic Improvement; Post Earthquake
\end{abstract}

\begin{abstract}
Abstrak
Masyarakat mengeluh usahanya terancam gagal yang menyebabkan perekonomian terganggu pasca bencana gempa. Tujuan penelitian ini untuk menemukan model komunikasi Corporate Social Responsibility (CSR) PT. Telkom untuk meningkatkan pemberdayaan ekonomi masyarakat korban gempa pada UKM di Sleman Yogyakarta. Metode penelitian ini menggunakan pendekatan subjektif dengan data kualitatif. Pengumpulan data dilakukan dengan interview dan FGD (Focus Group Discusion). Subjek penelitian ini adalah para pengusaha kecil menengah (UKM) yang menjadi korban gempa di Sleman Yogyakarta, dan tim CSR dari PT. Telkom Kandatel Yogyakarta. Analisis data dilakukan secara kualitatif dengan cara reduksi data, sajian data, serta penarikan kesimpulan. Hasil penelitian ini menemukan model komunikasi Corporate Social Responsibility (CSR) PT. Telkom untuk meningkatkan pemberdayaan ekonomi masyarakat korban gempa pada UKM di Sleman Yogyakarta. Kontribusi penelitian ini berupa rekomendasi kepada perusahaan-perusahaan pemerintah maupun swasta untuk menerapkan model komunikasi Corporate Social Responsibility (CSR) untuk meningkatkan pemberdayaan ekonomi masyarakat sekitar. Kata kunci: Model Komunikasi Corporate Social Responsibility (CSR) PT. Telkom; Peningkatan Ekonomi; Pasca Gempa
\end{abstract}

\section{Pendahuluan}

Daerah Istimewa Yogyakarta pada 27 Mei 2006 (Lestari, 2009) dilanda gempa bumi dasyat yang mengakibatkan 4.715 jiwa yang meninggal dan sekitar 20.000 jiwa yang mengalami luka berat dan ringan (Tabel 1). Tidak hanya korban jiwa, namun harta benda, rumah, sekolah, dan fasilitas umum mengalami kerusakan.

Tabel 1 menunjukkan bahwa korban terbesar dan fasilitas terbanyak yang mengalami kerusakan adalah Kabupaten Bantul dan diikuti
Sleman, Daerah Istimewa Yogyakarta (DIY). Banyak korban di antaranya para pengusaha kecil menengah (UKM) yang kehilangan mata pencahariannya. Kondisi tersebut mengetuk hati dan menggerakkan masyarakat yang tidak terkena bencana merasa simpati dan empati. Masyarakat yang tidak saling mengenal pun berduyun-duyun datang untuk ikut merasakan kepedihan dan penderitaan masyarakat DIY dan Jateng. Pada bulan pertama musibah gempa, berbagai bantuan muncul hampir setiap saat. 
Tabel 1. Data Korban Gempa DI. Yogyakarta per 24 Juni 2006

\begin{tabular}{lcclccccc}
\hline \multirow{2}{*}{ Lokasi } & \multicolumn{3}{c}{ Korban } & \multicolumn{4}{c}{ Kerusakan Rumah Penduduk } \\
& KK & Jiwa & Meninggal & Luka & Luka & Rusak & Rusak & Rusak \\
& & & & Berat & Ringan & Berat & Sedang & Ringan \\
\hline Bantul & $\mathbf{2 3 . 1 1 7}$ & $\mathbf{7 7 9 . 2 8 7}$ & $\mathbf{4 . 1 4 3}$ & $\mathbf{8 . 6 7 3}$ & $\mathbf{3 . 3 5 3}$ & $\mathbf{7 1 . 7 6 3}$ & $\mathbf{7 1 . 3 7 2}$ & $\mathbf{7 3 . 6 6 9}$ \\
Sleman & $\mathbf{9 5 . 8 6 5}$ & $\mathbf{3 6 5 . 0 3 8}$ & $\mathbf{2 4 6}$ & $\mathbf{6 7 8}$ & $\mathbf{3 . 0 9 9}$ & $\mathbf{1 9 . 1 1 3}$ & $\mathbf{2 7 . 6 8 7}$ & $\mathbf{4 9 . 0 6 5}$ \\
Jogja & 29.631 & 145.796 & 218 & 245 & 73 & 4.907 & 6.825 & 13.050 \\
Kulonprogo & 20.112 & 78.926 & 24 & 282 & 1.897 & 592 & 9.523 & 9.672 \\
Gunungkidul & 43.042 & 179.631 & 84 & 1.086 & 15 & 7.454 & 11.033 & 27.218 \\
Jumlah & $\mathbf{2 1 1 . 7 6 7}$ & $\mathbf{1 . 5 4 8 . 6 7 8}$ & $\mathbf{4 . 7 1 5}$ & $\mathbf{1 0 . 9 6 4}$ & $\mathbf{8 . 4 3 7}$ & $\mathbf{1 0 3 . 8 2 9}$ & $\mathbf{1 2 6 . 4 4 0}$ & $\mathbf{1 7 2 . 6 7 4}$ \\
\hline
\end{tabular}

Sumber: Tim Penanganan Bencana Propinsi DIY (2006)

Peristiwa ini membuka ruang komunikasi sosial antara masyarakat korban gempa dengan donatur atau relawan, lembaga pemerintah, perusahaanperusahaan swasta, dan donator lainnya. Banyak perusahaan milik pemerintah maupun swasta turut melakukan pendampingan dan pemulihan ekonomi masyarakat korban gempa, antara lain PT.Telkom. Sebagian perusahaan telah melakukan berbagai kegiatan pemulihan ekonomi masyarakat korban gempa melalui program CSR (Corporate Social Responsibility).

Berbagai kegiatan yang dilakukan oleh beberapa perusahaan memang baik, namun menurut hasil observasi pada Juni 2007, secara umum masih ditemukan banyak masalah berkaitan dengan pemberdayaan ekonomi masyarakat pasca gempa tersebut. Banyak masyarakat yang mengeluh usahanya terancam gagal, ada juga yang resah berkaitan dengan jaminan usaha yang diambil alih oleh bank, dan sebagainya. Hal ini membuktikan bahwa penanganan pemerintah terhadap pemberdayaan ekonomi masyarakat belum optimal, bahkan terkesan dibiarkan saja dan diselesaikan oleh waktu. Padahal, secara psikologis, kesulitan ekonomi yang berkepanjangan sangat mengganggu stabilitas kehidupan masyarakat. Hal ini menjadi perhatian bahwa diperlukan riset komunikasi untuk mengetahui perubahan kondisi ekonomi masyarakat yang berkaitan dengan program CSR (Corporate Social Responsibility). Mengingat prinsip program tersebut bersifat empowerment yaitu memberdayakan masyarakat menjadi mandiri secara ekonomi maupun sosial.
Peneliti telah melakukan penelitian mengenai model komunikasi Corporate Social Responsibility (CSR) Bank Indonesia (Lestari, 2009). Penelitian tersebut menemukan sinergis model komunikasi antara Bank Indonesia, pemerintah, dan masyarakat melalui Program CSR. Program CSR BI telah memenuhi sistematika program CSR, yaitu komunikasi yang diadakan antara perusahaan, pemerintah, dan mitra binaan, yaitu UKM Manding sentra industri sudah intensif, melalui pertemuan resmi, meninjau dan secara informal melalui telepon. Program CSR dilakukan termasuk berhasil dalam outsourcing UKM pasca gempa di Manding, Kabupaten Bantul. Sumber daya manusia yang telah mengikuti kursus bahasa Inggris dan komputer, pembangunan fisik berupa tempat parkir, ATM, gedung pertemuan, gerbang sebagai identitas sebagai surat sentra kerajinan Manding, dan baliho tentang Manding, ada banyak keramaian toko yang dikunjungi oleh konsumen dalam dan luar negeri.

Penelitian Gussman, Fathonah, dan Wibawa (2009) tentang analisis community development PT. Telkom Kandatel Yogyakarta dalam pengembangan UKM melalui program kemitraan. Hasil penelitian tersebut menunjukkan bahwa faktor keberhasilan agar berhasil menjalankan program kemitraan yaitu adanya program dan dana yang terencana dan kerjasama antara Telkom dan mitra binaan serta dukungan pemerintah dan masyarakat. Kunci sukses dalam menjalankan program yaitu dengan memerhatikan penyaluran, pemanfaatan, pengembalian, dan pengambangan usaha ekonomi produksi masyarakat. 
Penelitian yang berkaitan dengan program CSR terhadap kesejahteraan hidup masyarakat dilakukan oleh Mapisangka (2009). Hasil penelitian tersebut menunjukkan bahwa kebijakan penerapan program CSR pada PT. Investasi Batamindo Cakrawala harus berfokus pada nilai- nilai sosial lokal. Pendekatan tersebut dilakukan agar perusahaan berjalan secara efektif dan efisien. Program CSR wajib melibatkan seluruh masyarakat di lingkungan perusahaan, sehingga dapat memanfaatkan program CSR tersebut.

Tabel 2 Daftar Beberapa Perusahaan yang melakukan CSR

\begin{tabular}{|c|c|c|c|c|c|c|c|}
\hline & Program & Kegiatan & Sasaran & $\begin{array}{c}\text { Lokasi, } \\
\text { skala }\end{array}$ & Waktu & Dana & $\begin{array}{c}\text { Cakupan } \\
3 \mathrm{P}\end{array}$ \\
\hline $\begin{array}{c}\text { PT. } \\
\text { Indosat } \\
\text { Tbk. }\end{array}$ & $\begin{array}{l}\text { "Indonesia } \\
\text { Belajar" }\end{array}$ & $\begin{array}{c}\text { I-WIC } \\
\text { (Indosat } \\
\text { Wireless } \\
\text { Innovation } \\
\text { Contest) }\end{array}$ & $\begin{array}{c}\text { Siswa } \\
\text { SMP/SMA } \\
\text { Mahasiswa } \\
\text { umum }\end{array}$ & $\begin{array}{c}\text { Jakarta, } \\
\text { Nasional }\end{array}$ & 2006 & Tak tertera & $\begin{array}{c}\text { People, } \\
\text { profit }\end{array}$ \\
\hline $\begin{array}{l}\text { PT Astra } \\
\text { Honda } \\
\text { Motor } \\
\text { (AHM) }\end{array}$ & Safety Riding & $\begin{array}{l}\text { Promosi } \\
\text { Honda Riding } \\
\text { Trainer } \\
\text { (HRT) }\end{array}$ & $\begin{array}{c}\text { Pengguna } \\
\text { sepeda } \\
\text { motor } \\
\text { Honda: } \\
\text { siswa, } \\
\text { mahasiswa } \\
\text {, PNS, } \\
\text { karyawan } \\
\text { swasta }\end{array}$ & $\begin{array}{c}\text { Dealer } \\
\text { seluruh } \\
\text { Indonesia, } \\
\text { nasional }\end{array}$ & 2006 & Tak tertera & $\begin{array}{l}\text { People, } \\
\text { profit }\end{array}$ \\
\hline PT Inco & $\begin{array}{l}\text { Rehabilitasi } \\
\text { lahan paca- } \\
\text { tambang }\end{array}$ & Pembibitan & $\begin{array}{l}\text { Penduduk } \\
\text { lokal, } \\
\text { rehabilitasi } \\
\text { lahan }\end{array}$ & $\begin{array}{c}\text { Pontada, } \\
\text { Sorowak, } \\
\text { Luwu } \\
\text { Timur, } \\
\text { Sultengg }\end{array}$ & - & Tak tertera & $3 \mathrm{P}$ \\
\hline $\begin{array}{l}\text { LG } \\
\text { Electrinics } \\
\text { Indonesia }\end{array}$ & $\begin{array}{c}\text { LG Love \& } \\
\text { Care, Love } \\
\text { School }\end{array}$ & $\begin{array}{c}\text { Bantuan } \\
\text { korban banjir, } \\
\text { gempa \& } \\
\text { tsunami, } \\
\text { family day, } \\
\text { bantuan } \\
\text { fasilitas dan } \\
\text { ruang } \\
\text { pendidikan, } \\
\text { disamping } \\
\text { bantuan } \\
\text { pendidikan } \\
\text { kesehatan dan } \\
\text { sosial }\end{array}$ & $\begin{array}{l}\text { Kurban } \\
\text { banjir, } \\
\text { gempa dan } \\
\text { tsunami }\end{array}$ & $\begin{array}{l}\text { Jakarta, } \\
\text { DIY, } \\
\text { NAD }\end{array}$ & 1990-kini & Tak tertera & $\begin{array}{l}\text { People, } \\
\text { profit }\end{array}$ \\
\hline $\begin{array}{l}\text { PT Jasa } \\
\text { Marga }\end{array}$ & $\begin{array}{c}\text { Program } \\
\text { Kemitraan } \\
\text { dan Bina } \\
\text { Lingkungan } \\
\text { (PKBL) }\end{array}$ & $\begin{array}{l}\text { Peminjaman } \\
\text { modal kerja, } \\
\text { bantuan bina } \\
\text { lingkungan, } \\
\text { pembagian } \\
\text { sembako, } \\
\text { bangun sarana } \\
\text { ibadah, } \\
\text { khitanan } \\
\text { massal, } \\
\text { beasiswa, } \\
\text { relawan } \\
\text { bencana alam, } \\
\text { MCK, } \\
\text { peningkatan } \\
\text { kualitas jalan, } \\
\text { sumber daya } \\
\text { \& saluran air } \\
\text { bersih, } \\
\text { drainase } \\
\text { standar amdal. }\end{array}$ & $\begin{array}{l}\text { Penduduk } \\
\text { sekitar } \\
\text { jalan tol, } \\
408 \text { mitra } \\
\text { binaan, } \\
\text { korban } \\
\text { bencana } \\
\text { alam }\end{array}$ & Nasional & $\begin{array}{c}\text { Sejak } \\
\text { pembangunan } \\
\text { jalan tol-kini }\end{array}$ & $\begin{array}{c}\text { Rp 1,168 } \\
\text { miliar } \\
\text { (PKBL, } \\
2006) ; \text { Rp } \\
2,5 \text { miliar } \\
\text { (Aceh \& } \\
\text { Nias); Rp } \\
108 \text { juta } \\
\text { (renovasi } \\
\text { SD } \\
\text { Bantul) }\end{array}$ & $\begin{array}{c}\text { People } \\
\text { profit }\end{array}$ \\
\hline
\end{tabular}




\begin{tabular}{|c|c|c|c|c|c|c|c|}
\hline & Program & Kegiatan & Sasaran & $\begin{array}{c}\text { Lokasi, } \\
\text { skala }\end{array}$ & Waktu & Dana & $\begin{array}{c}\text { Cakupan } \\
3 \mathrm{P}\end{array}$ \\
\hline $\begin{array}{l}\text { Dirjen } \\
\text { Cipta } \\
\text { Karya }\end{array}$ & $\begin{array}{c}\text { Kampong } \\
\text { Improvement, } \\
\text { P2KP, BKM, } \\
\text { PJM- } \\
\text { Pronangkis, } \\
\text { BLM, PNPM }\end{array}$ & $\begin{array}{c}\text { Perbaikan } \\
\text { infrastruktur } \\
\text { daerah } \\
\text { kumuh, } \\
\text { bangun } \\
\text { kebersamaan } \\
\text { \& capital } \\
\text { social, } \\
\text { pembangunan } \\
\text { wilayah, } \\
\text { swakelola } \\
\text { dana bantuan }\end{array}$ & $\begin{array}{l}\text { Penduduk } \\
\text { miskin, } \\
\text { lebih } 3 \text { juta } \\
\text { keluarga } \\
\text { pra- } \\
\text { sejahtera I }\end{array}$ & $\begin{array}{c}30 \\
\text { provinsi, } \\
6.406 \\
\text { BKM, 240 } \\
\text { kota, } \\
\text { nasional }\end{array}$ & 1999-kini & $\begin{array}{c}\text { Rp 1,7 } \\
\text { trilyun } \\
\text { (BLM), } \\
2,5 \% \\
\text { profit } \\
\text { untuk } \\
\text { BKM }\end{array}$ & $3 \mathrm{P}$ \\
\hline $\begin{array}{l}\text { PT Sun } \\
\text { Life } \\
\text { Financial } \\
\text { Indonesia }\end{array}$ & Sunbright & $\begin{array}{c}\text { Sumbangan } \\
\text { buku, } \\
\text { beasiswa, } \\
\text { bangun } \\
\text { gedung }\end{array}$ & $\begin{array}{c}\text { SDN, } \\
\text { mahasiswa } \\
\text { PTN }\end{array}$ & $\begin{array}{c}\text { Jakarta, } \\
\text { Surabaya, } \\
\text { Medan, } \\
\text { SDN } \\
\text { Sidomoro } \\
\text { Bantul }\end{array}$ & - & $\begin{array}{c}1.100 \\
\text { buku, dana } \\
\text { tak tertera }\end{array}$ & people \\
\hline
\end{tabular}

Sumber: Majalah Tempo April (2007)

Perbedaan penelitian ini dengan penelitian terdahulu adalah fokus penelitian pada model komunikasi perusahaan dan masyarakat melalui program CSR PT. Telkom untuk meningkatkan pemberdayaan ekonomi masyarakat pasca gempa pada UKM di Sleman Yogyakarta. Hal ini terlihat pentingnya perusahaan melibatkan stakeholder dalam menjalankan program pemberdayaan ekonomi masyarakat.

\section{Teori Stakeholder}

Penelitian ini menggunakan Teori Stakeholder yang merupakan kerangka berpikir dalam memahami kaitan antara bisnis dengan masyarakat serta strategi manajemen bisnis yang digunakan dalam CSR (Rahardja, Zain, Salim, \& Rahayu, 2012). Hal ini terlihat bahwa adanya keterlibatan banyak aktor dalam bisnis yang memiliki kepentingan tersebut (Purnomo, 2010). Teori Stakeholder menerangkan bahwa CSR yang dilakukan oleh suatu perusahaan merupakan salah satu cara untuk melakukan komunikasi dengan stakeholder. Salah satu prinsip penting yang mendasar dari Teori Stakeholder yaitu suatu organisasi harus memenuhi kebutuhan secara luas dari keinginan stakeholder dalam pencapaiannya melebihi stockholders (pemilik perusahaan) (Riyantie,
2013). Hal ini terlihat bahwa Teori Stakeholder menekankan pentingnya bisnis dalam kerangka kerja sosial yang mendukung konsep CSR.

\section{Konsep Corporate Social Responsibility (CSR)}

Penelitian ini mengaitkan pada konsep Corporate Social Responsibility (CSR) dengan PT. Telkom. CSR merupakan komitmen suatu perusahaan dalam berkontribusi membangun ekonomi yang berkelanjutan, kerja sama perusahaan dan karyawan, komunitas lokal, dan komunitas lain untuk meningkatkan kehidupan (Anatan, 2010). CSR salah satu wujud partisipasi dari dunia usaha dalam pembangunan berkelanjutan untuk mengembangkan program kepedulian perusahaan kepada masyarakat sekitar melalui penciptaan dan pemeliharaan keseimbangan antara mencetak keuntungan, fungsi-fungsi sosial, dan pemeliharaan lingkungan hidup. Ada empat hal yang menjadi penting dalam CSR yaitu ekonomi, hukum, etika, dan filantropi. Hal ini dinilai penting untuk diperhatikan bagi perusahaan yang bermaksud menggunakan CSR untuk tujuan strategis (Ramasamy \& Yeung, 2009. CSR masih perlu berkembang di tahap awal pelaksanaan di Indonesia, hal ini perlu adanya pendekatan. Pendekatan CSR di negara berkembang yang 
dinilai sangat memberikan pengaruh kuat adalah pendekatan infrastruktur kelembagaan dan etika budaya (Yin \& Zhang, 2012). Budaya yang perlu diperhatikan PT. Telkom Kendatel Yogyakarta adalah berkaitan dengan lingkungan eksternal, yaitu masyarakat Yogyakarta, khususnya di Sleman. Lingkungan ekternal pada perusahaan berkaitan dengan Teori Sistem.

\section{Teori Sistem (General System Theory)}

Teori Sistem (General System Theory) merupakan adanya interactive social system antara perusahaan dan masyarakat yang saling membutuhkan dan memengaruhi. Korporat merupakan bagian dari masyarakat, serta masyarakat merupakan bagian dalam bisnis perusahaan yang seringkali memengaruhi keputusan perusahaan(Lestari, 2009). Perusahaan harus dapat beradaptasi terhadap lingkungan eksternal. Hal inilah yang menjadi dasar perusahaan untuk bertahan pada kemampuan beradaptasi dan perubahan lingkungan untuk meningkatkan kehidupan perusahaan. Pada penelitian ini masyarakat sekitar perusahaan yang mengalami keterpurukan ekonomi akibat musibah gempa pada tanggal 27 Mei 2007.

Praktek CSR oleh banyak perusahaan di Indonesia mengalami peningkatan pada kurun dasa warsa terakhir. Pengamat CSR melihat sekitar 30\%-40 \% yang telah menjalankan CSR, dari total jumlah perusahaan dan usaha sebanyak 22,7 juta, di luar perusahaan atau usaha pertanian (Tabel 2).

Aktivitas CSR memiliki beragam bentuk, antara lain dengan mendirikan lembaga khusus sebagai pelaksana maupun konsultan, membentuk divisi khusus CSR di bawah direktorat, pembentukan perkumpulan perusahaan yang telah menjalankan CSR, dan menyelenggarakan CSR Awards (Tabel 3).

Perusahaan merasa aman terhadap stakeholder, yang mewakili masing-masing pilihan dari 3P Profit (keuntungan ekonomi), People (peduli manusia) dan Planet (peduli lingkungan hidup) (Lestari, 2009). Berdasarkan latar belakang yang ada, penelitian ini bertujuan untuk untuk menemukan model komunikasi Corporate Social Responsibility (CSR) PT. Telkom untuk meningkatkan pemberdayaan ekonomi masyarakat korban gempa pada UKM di Sleman Yogyakarta.

\section{Metode Penelitian}

Penelitian ini menggunakan pendekatan subjektif dengan jenis data kualitatif. Objek penelitian adalah model komunikasi Corporate Social Responsibility (CSR) PT. Telkom untuk meningkatkan pemberdayaan ekonomi masyarakat korban gempa pada UKM di Sleman Yogyakarta. Subjek penelitian ini, yaitu para pengusaha kecil menengah (UKM) yang menjadi mitra binaan PT.Telkom di Sleman Yogyakarta dan tim CSR dari PT.Telkom Yogyakarta. Jenis data yang digunakan dalam penelitian ini, yaiut: a) Data primer yang mencakup hasil wawancara mendalam dan hasil Focus Group Discussion (FGD) dengan para informan (subjek penelitian); dan b) Data sekunder dari berbagai dokumen terkait tentang CSR dan pemberdayaan ekonomi masyarakat akibat musibah gempa. Teknik Pengambilan Sampel dilakukan secara purpusive sampling, dengan kriteria, yaitu: Pengusaha kecil menengah (UKM) yang terkena musibah gempa, tinggal di Sleman, dan menjadi Mitra Binaan PT. Telkom.

Penelitian ini menggunakan teknik pengumpulan data dengan wawancara mendalam kepada informan penelitian yaitu masyarakat UKM korban gempa, Tim CSR PT. Telkom; dan Focus Group Discusion (FGD) dari informan dan Tim CSR PT. Telkom. Pada FGD diambil informan berdasarkan hasil wawancara mendalam yang dapat mewakili kelompoknya. Teknik analisis data Miles \& Huberman dilakukan dengan: a) Reduksi data dengan melakukan pemilihan data saat pengumpulan data berlangsung, reduksi data dilakukan dengan membuat ringkasan catatan data lapangan; b) Sajian data dalam bentuk gambar dan tabel sebagai 
Tabel 3 Perusahaan dan Program CSR

\begin{tabular}{|c|c|}
\hline Perusahaan & Program-program CSR \\
\hline CITIBANK & $\begin{array}{l}\text { CITIBANK "PEDULI \& BERKARYA" (PEKA): Pendidikan Generasi } \\
\text { Muda; Pendidikan Keuangan; Pembangunan Komunitas \& Kewirausahaan; } \\
\text { Lingkungan; Bantuan Bencana Alam; Program Relawan Karyawan }\end{array}$ \\
\hline PT. HM SAMPOERNA & $\begin{array}{l}\text { Program Pusat Pelatihan Kewirausahaan Sampoerna; Program Sampoerna } \\
\text { Rescue; Program Pemberdayaan Masyarakat Desa; Program Bimbingan } \\
\text { Anak Sampoerna; Peningkatan Kualitas Sekolah ; Program Mitra Produksi } \\
\text { Sigaret; Program Kemitraan Petani Tembakau; Program Penyediaan Air } \\
\text { Bersih Untuk Masyarakat; Program Ijo Royo-Royo, Penanaman Sejuta } \\
\text { Pohon }\end{array}$ \\
\hline COCA-COLA & $\begin{array}{l}\text { Program CSR Spesifik Lokal; Program Nasional (Coca-Cola Foundations), } \\
\text { Yaitu: Rumah Belajar; Program Penyediaan IT; Program Pendidikan HIV } \\
\text { AIDS Bagi Remaja; Program Pendidikan Lingkungan; Pelatihanpenulisan } \\
\text { Cerita Anak; Penerbitan Seri Buku Keanekaragaman Hayati Atau Cerita } \\
\text { Anak }\end{array}$ \\
\hline KALBE FARMA & $\begin{array}{l}\text { Beasiswa Bagi Karyawan; Program Bagi Anak-Anak Putus Sekolah; } \\
\text { Pengobatan Gratis; Puskesmas Keliling Procold; Promag Mulia; Woods } \\
\text { Pelangi Polusi; Cerebrofot Peduli Anak Bangsa }\end{array}$ \\
\hline UNILEVER INDONESIA & $\begin{array}{l}\text { Public Health Education (Lifebuoy - Handwashing Campaign, Pepsodent } \\
\text { - Initative For Dental Health, Domestos Nomos - Malaria Prevention; } \\
\text { Surabaya Environment Program; Program Pengembangan Petani Kedelai } \\
\text { Hitam }\end{array}$ \\
\hline RIAU ANDALAN & Program Pengembangan Sistem Pertanian Terpadu; Social \& \\
\hline PULP \& PAPER & $\begin{array}{l}\text { Infrastructure; Small And Medium Enterprises: Partnership; Vocational } \\
\text { Training }\end{array}$ \\
\hline
\end{tabular}

Sumber: Majalah MIX (16 Oktober - 16 November 2006)

pendukung narasi; dan c) penarikan kesimpulan dan verifikasi dari penelitian ini berupa model komunikasi perusahaan dan masyarakat melalui program CSR PT. Telkom pada UKM di Sleman Yogyakarta. Hasil ini untuk direkomendasikan kepada institusi pemerintah atau pihak swasta terkait, khususnya kepada PT. Telkom.

\section{Hasil Penelitian dan Pembahasan}

Hasil wawancara dengan Bapak H. Musrin yang merupakan seorang petani salak di Sleman. "Awal mula budidaya salak dimulai tahun 1982, namun belum berupa salak pondoh, masih salak biasa yang rasanya agak sepet. Baru setelah ditemukan 2 pohon salak secara tidak terduga yang rasanya manis, kemudian mulai dilakukan pencangkokan dan dilakukan pengembangan budidaya salak pondoh dilakukan. Tahun 1985 mulai berhasil melakukan panen, yang kemudian diawali dengan penjualan harga yang cukup baik" (Bapak H. Musrin, 17 Juni 2007). Penjualan dengan melihat harga salak yang mulai membaik, menjadi langkah awal buah salak mulai dikembangkan dengan cara membentuk kelompok tani yang berjumlah 30 orang. Kelompok tani ini diberikan bantuan sejumlah
100 batang benih salak pondoh, dari 100 batang pohon tersebut dianjurkan hasil anakan salak dikembangkan lagi menjadi benih. Budidaya salak pondoh ini menunjukkan keberhasilan, dengan perolehan GAP (Good Agriculture Practice). "Kemudian BTTP Propinsi Daerah Istimewa Yogyakarta tahun 2004 mengajak Telkom untuk membantu pengembangan budidaya salak pondoh ini. Pada awalnya dibentuk satu kelompok yang beranggotakan 8 orang dengan perantara Dinas Pertanian yang menjadi penghubung Telkom, untuk memperoleh bantuan dana pengembangan. Jadi Dinas Pertanian yang memberikan rekomendasi ke Telkom untuk menentukan petani yang dapat memperoleh bantuan. Bantuan pertama yang diberikan adalah sejumlah Rp. 5.000.000 per anggota kelompok. Setelah bantuan bergulir sampai dengan 20 orang, dan berjalan dengan lancar, bantuan kembeli ditawarkan, sehingga mencapai 146 anggota yang memperoleh bantuan" (Bapak H. Musrin, 17 Juni 2007). Hal ini dililihat baik, sehingga untuk saat ini pemberian rekomendasi diserahkan pada kelompok, dan bantuan yang diberikan minimal sebesar Rp. 10.000.000. Pada tahun 2005, petani salak pondoh kembali memperoleh penghargaan, yaitu dari Presiden RI Susilo Bambang Yudhoyono. Sebagai wujud tanggungjawab 
sosial, Telkom pada tahun 2006 mulai melakukan kegiatan bina lingkungan, dengan melakukan beberapa penataan lingkungan yang dianggap mampu mendukung pengembangan bisnis salak pondoh, antara lain dengan membuat Gardu pandang Merapi. Dinas Pariwisata juga memberikan dukungan dengan membuat jalan, sehingga diharapkan budidaya salak pondoh bisa dikembangkan sebagai bisnis wisata pertanian. "Kami (para petani) supaya menunjang keberhasilan, diikut sertakan dalam berbagai kegiatan pameran pertanian di berbagai daerah, supaya salak pondoh semakin dikenal dan pemasaran distribusinya semakin meluas. Dukungan yang selama ini diberikan oleh Telkom, diharapkan oleh para petani bisa dilakukan secara berkelanjutan mengingat kebutuhan petani seiring dengan meluasnya pemasaran juga semakin tinggi” (Bapak H. Musrin, 17 Juni 2007). Bantuan yang diberikan kepada para petani sebisa mungkin mengacu pada kebutuhan dasar petani, misalnya untuk saat ini yang dibutuhkan adalah adanya saluran air, yang bisa membantu petani untuk dapat memanen salak sewaktuwaktu. Bantuan lain yang diberikan Telkom seiring dengan meningkatnya pemasaran adalah pelatihan manajemen keuangan bagi pengurus kelompok tani. Hubungan yang diberlakukan Telkom bagi para petani berupa hubungan kekeluargaan, namun nampaknya pergantian pejabat Telkom cukup memengaruhi hubungan dan monitoring yang dilakukan oleh Telkom.

Hal ini terlihat bahwa setelah pejabat yang menangani CSR digantikan, tampak hubungan yang terjalin tidak dapat berkelanjutan, karena terlihat ada yang terputus dari hubungan yang selama ini terjalin. Hal ini apabila tidak segera ditindaklanjuti, tentunya dapat merusak hubungan baik yang selama ini sudah terjaga. Pengembangan saat ini, Telkom menawarkan pinjaman dengan bunga $6 \%$ pertahun. Pengembangan terus dilakukan untuk memenuhi standar Internasional, yaitu dengan membuat sertifikasi yang dipantau oleh Otoritas Kompetensi Daerah Dinas Pertanian DIY. Hal ini mengingat sampai saat ini salak pondoh sudah mulai diekspor ke Cina.
Hasil wawancara pada 17 Juni, 2007 menyatakan:

"PT. Telkom Kandatel Yogyakarta memiliki program CSR (Corporate Social Responsibility) di bawah koordinasi Manager Public Relations. Wilayah yang digarap meliputi seluruh kabupaten di D.I.Yogyakarta plus eks. Karisedenan Kedu (termasuk Magelang, Purworejo dan sekitarnya). Walaupun koordinasi ada pada divisi Public Relations, pelaksanaan program-programnya dilakukan oleh divisi CDC (Community Developement Centre). Informasi lebih detail ada pada divisi tersebut" (Manager Public Relations PT.Telkom Kandatel Yogyakarta, 17 Juni 2007).

Perihal program pemberdayaan ekonomi masyarakat pasca gempa, dapat diperoleh informasi dari divisi CDC (Community Developement Centre) PT. Telkom Kandatel Yogyakarta sebagai berikut:

"Kami telah memiliki ribuan mitra binaan, yang bergerak pada pemberdayaan ekonomi masyarakat, baik di Bantul, Gunungkidul, Kulonprogo, Sleman maupun wilayah Purworejo dan sekitarnya. Perusahaan telah memberikan pinjaman sangat lunak kepada semua warga masyarakat yang memerlukan modal usaha untuk pemulihan ekonominya. Di samping itu perusahaan juga memberikan berbagai pelatihan, kesempatan untuk pameran produk, pemasaran bahkan melakukan pengawasan secara berkala atas kemajuan usaha tersebut, yang tujuannya untuk meningkatkan pemberdayaan ekonomi masyarakat. Pada kondisi pasca gempa 27 Mei 2006, mitra binaan kami semakin bertambah, lebih-lebih di Bantul ada sekitar 600 -an orang sedang di Sleman ada sekitar 200-an orang" (Tim CDC Telkom Kandatel Yogyakarta, 17 Juni, 2007).

Model pelaksanaan CSR PT. Telkom Kandatel Yogyakarta melakukannya dalam bentuk Telkom Peduli dengan terlibat langsung tanpa perantara. Melalui koordinasi Public Relations dan dilaksanakan oleh Tim Community Development Centre (CDC) (Gambar 1).

Model 1 berdasarkan empat model atau pola CSR yang umumnya diterapkanoleh perusahaandi Indonesia (Soesilowati, Indriyanti, \& Widiyanto, 2011), yakni: 1) Keterlibatan Langsung: 


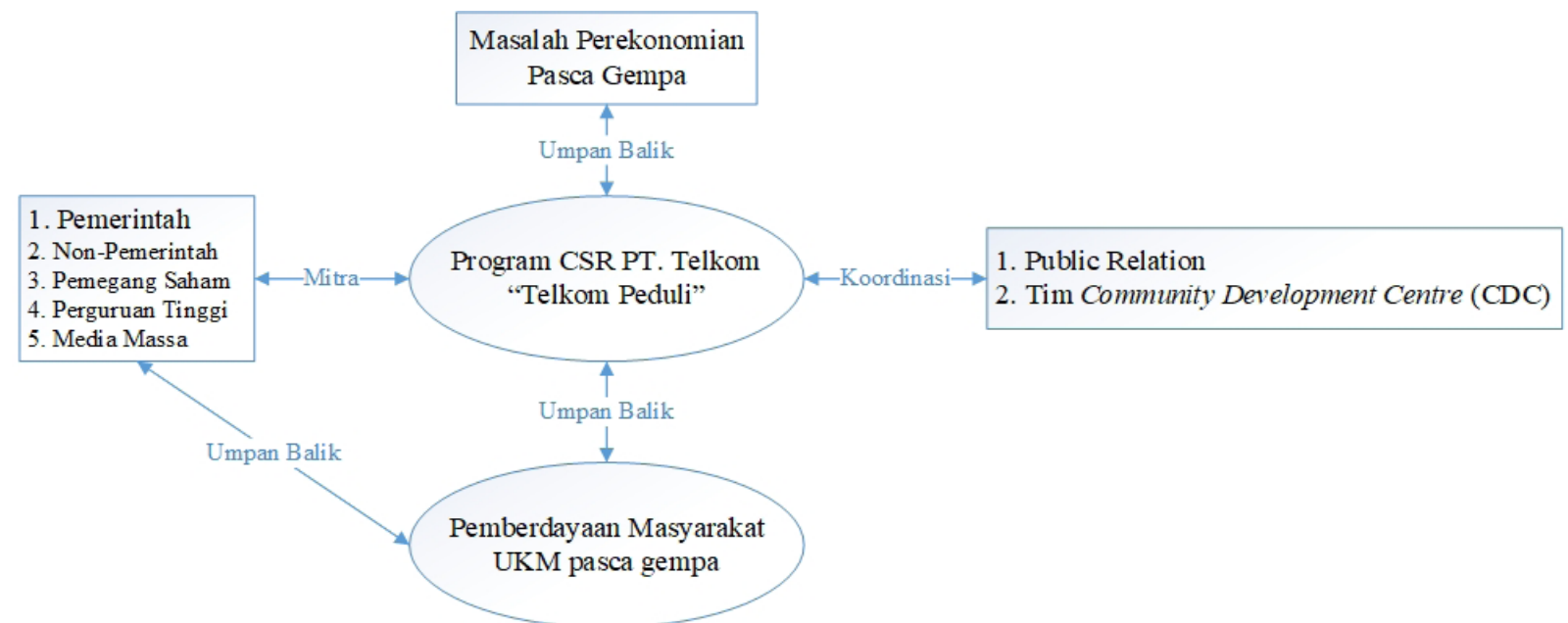

Gambar 1 Model komunikasi Corporate Social Responsibility (CSR) PT. Telkom untuk meningkatkan Pemberdayaan Ekonomi Masyarakat Korban Gempa Pada UKM di Sleman Yogyakarta

Sumber: Hasil analisis peneliti (2013)

perusahaan menjalankan Program CSR secara langsung dengan cara menyelenggarakan sendiri kegiatan sosial atau menyerahkan sumbangan ke masyarakat tanpa perantara. Untuk menjalankan tugas ini, sebuah perusahaan biasanya menugaskan para pejabatnya, seperti corporate secretary atau public relations.

2) Melalui yayasan atau organisasi sosial perusahaan. Perusahaan mendirikan yayasan sendiri di bawah perusahaan atau groupnya. Model ini merupakan adopsi dari model yang lazim diterapkan oleh perusahaan-perusahaan di negara maju. Biasanya perusahaan menyediakan dana awal, dana rutin, atau dana abadi yang dapat digunakan secara teratur bagi kegiatan yayasan. Contohnya Yayasan Coca-Cola Company, Yayasan Rio Tinto, Yayasan Sahabat Aqua, GE Fund, Yayasan Sampoerna. 3) Bermitra dengan pihak lain. Perusahaan menyelenggarakan CSR melalui kerja sama dengan lembaga sosial atau organisasi nonpemerintah, instansi pemerintah, universitas atau media massa, baik dalam mengelola dan maupun dalam melaksanakan kegiatan sosialnya. Misalnya Palang Merah Indonesia, Dompet Dhuafa, instansi pemerintah (LIPI, Depdiknas, Depkes, Depsos), Universitas dan media massa (DKK Kompas, Kita Peduli
Indosiar). 4) Mendukung atau bergabung dalam suatu konsorsium. Perusahaan turut mendirikan, menjadi anggota atau mendukung suatu lembaga sosial yang didirikan untuk tujuan sosial tertentu. Pola ini lebih beorientasi pada pemberian hibah perusahaan yang bersifat "hibah Pembangunan". Pihak konsorsium atau lembaga semacam itu yang dipercaya oleh perusahaan yang mendukungnya secara proaktif mencari mitra kerjasama dari kalangan lembaga operasional dan kemudian mengembangkan program yang disepakati bersama.

Model komunikasi perusahaan dan masyarakat melalui program CSR PT. Telkom pada UKM di Bantul dan Sleman Yogyakarta penting untuk dilakukan karena dampaknya bagi masyarakat memengaruhi proses pembangunan masyarakat pada umumnya. Hal ini mendukung penelitian yang dilakukan oleh Usop (2012) yang menyatakan bahwa perusahaan perlu mengerahkan partisipasi aktif masyarakat dalam menciptakan Corporate Social Responsibility (CSR). Penelitian lain yang dilakukan oleh Hanggarwati dan Mutmainah (2013) menyatakan bahwa program CSR yang berpengaruh positif dan signifikan terhadap kepemilikan perusahaan dalam meningkatkan kualitas kehidupan dengan memerhatikan stakholder. 


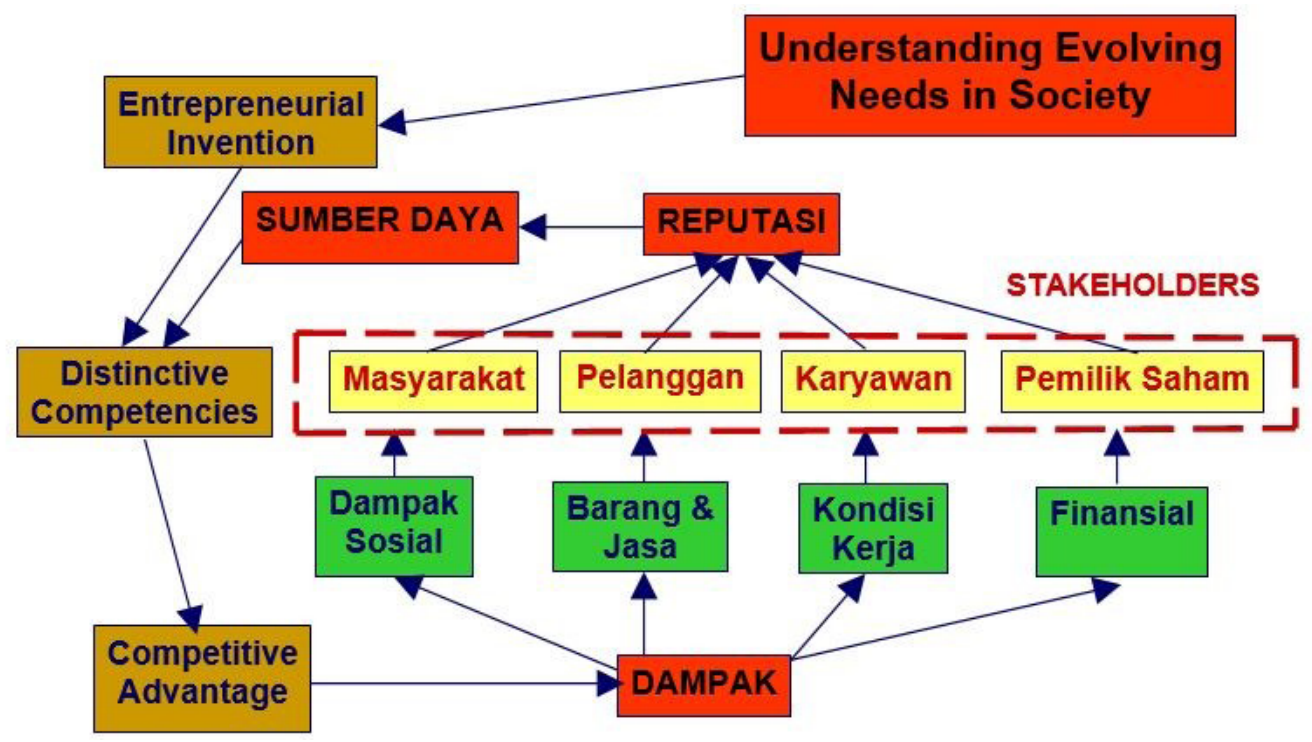

Gambar 2 Interaksi Perusahan dengan Stakeholders

Sumber: Peter Schwarz \& Blair Gibb (Lestari, 2009)

Gambar 2 menunjukkan bahwa perusahaan pada dasarnya selalu berhubungan dengan stakeholder utama yaitu para pemegang saham, pelanggan, karyawan, pemerintah dan masyarakat. Stakeholder sekunder yaitu serikat kerja, kreditor, partai politik, kelompok agama, institusi pendidikan, kaum miskin, media, pemasok adalah merupakan stakeholder yang dijalin namun tidak diutamakan. Stakeholder utama merupakan stakeholder yang diprioritaskan untuk dijalin terutama karena dianggap sebagai unsur penting bagi perusahaan di masa yang akan datang. Masyarakat sebagai salah satu stakeholder yang diutamakan, dianggap sebagai pihak yang harus dijalin dan upaya yang dapat dilakukan adalah dengan menerapkan community development, dalam upaya pemberdayaan ekonomi masyarakat yang dampaknya memengaruhi proses pembangunan masyarakat pada umumnya. Hal ini relevan dengan Teori Stakeholder yang menyatakan bahwa stakeholder merupakan hal penting yang menyukseskan perusahaan (Nur \& Priantinah, 2012) dalam menjalankan program CSR. Program CSR pasca gempa bumi menjadikan masyarakat yang mandiri dalam hal intelektual, manajemen dan ekonomi sehingga meningkatkan potensi ekonomi daerah yang berdampak pada kesejahteraan masyarakat yang terus meningkat. Program CSR PT. Telkom yang dijadikan model komunikasi program CSR yang dapat diterapkan di perusahaan lain untuk meningkatkan pemberdayaan ekonomi masyarakat setempat.

\section{Simpulan}

Penelitian ini menemukan model komunikasi Corporate Social Responsibility (CSR) PT. Telkom untuk meningkatkan pemberdayaan ekonomi masyarakat korban gempa pada UKM di di Bantul dan Sleman Yogyakarta. Program CSR ini menjadikan masyarakat yang mandiri dalam meningkatkan potensi ekonomi dearah masing-masing untuk menyejahteraan kehidupan. Kontribusi penelitian ini berupa rekomendasi kepada perusahaan-perusahaan pemerintah maupun swasta, tentang model komunikasi perusahaan dan masyarakat untuk pemberdayaan ekonomi melalui program CSR (Corporate Social Responsibility) yang tepat sasaran. 


\section{Daftar Pustaka}

Anatan, L. (2010). Coorporate Social Responsibility (CSR): Tinjauan Teoritis dan Praktik di Indonesia. Jurnal Manajemen Maranatha, 8(2), 66-77. https://doi.org/10.28932/jmm.v8i2.192

Gussman, S. Y., Fathonah, S., \& Wibawa, A. (2009). Analisis Community Development PT. Telkom Kandatel Yogyakarta dalam Pengembangan UKM melalui Program Kemitraan. Jurnal Ilmu Komunikasi, 7(1), 16-28. Diakses dari http://jurnal.upnyk. ac.id/index.php/komunikasi/article/view/11

Hanggarwati, K., \& Mutmainah, S. (2013). Analisis Pengaruh Pengungkapan Corporate Social Responsibility Terhadap Institutional Ownership. Diponegoro Journal of Accounting, 2(2), 475-483. Diakses dari https://ejournal3.undip.ac.id/ index.php/accounting/article/view/3296

Lestari, P. (2009). Model Komunikasi Corporate Social Responsibility (CSR) Bank Indonesia. Jurnal Ilmu Komunikasi, 7(3), 291-300. Diakses dari http://jurnal.upnyk.ac.id/ index.php/komunikasi/article/view/26 Mapisangka, A. (2009). Implementasi CSR terhadap Kesejahteraan Hidup Masyarakat. JESP: JurnalEkonomi \& Studi Pembangunan, 1(1), 39-47. Diakses dari http://journal. um.ac.id/index.php/jesp/article/view/5123

Nur, M., \& Priantinah, D. (2012). Analisis Faktor-Faktor Yang Mempengaruhi PengungkapancorporateSocialResponsibility Di Indonesia (Studi Empiris Pada Perusahaan Berkategori High Profile Yang Listing Di Bursa Efek Indonesia). Nominal: Barometer Riset Akuntansi dan Manajemen, 1(2), 22-34. https://doi.org/10.21831/nominal.v1i2.996 Purnomo, E. P. (2010). Development of Local Institutions towards on Participation and
Communication Model in the United Kingdom. Jurnal Ilmu Komunikasi, 8(3), 280-288. Diakses dari http://jurnal.upnyk. ac.id/index.php/komunikasi/article/view/132 Rahardja, E., Zain, D., Salim, U., \& Rahayu, M. (2012). Implementasi Corporate Social Responsibility dan Implikasinya dalam Perspektif Teori Stakeholder (Studi pada Perusahaan Tekstil dan Produk Tekstil di Jawa Tengah). Jurnal Aplikasi Manajemen, 9(2), 535-544. Diakses dari https://jurnaljam. ub.ac.id/index.php/jam/article/view/247 Ramasamy, B., \& Yeung, M. (2009). Chinese consumers' perception of corporate social responsibility (CSR). Journal of Business Ethics, 88(1), 119-132. https:// doi.org/10.1007/s $10551-008-9825-\mathrm{x}$ Riyantie, M. (2013). Implementasi CSR melalui Program "Kampoeng BNI" oleh PT. BNI (Persero) TBK. Jurnal Kajian Komunikasi, 1(2), 186-195. http:// dx.doi.org/10.24198/jkk.v1i2.6043 Soesilowati, E., Indriyanti, D. R., \& Widiyanto, W. (2011). Model Corporate Social Responsibility Dalam Program Pemberdayaan Petani Hortikultura. Jurnal Ekonomi Pembangunan: Kajian Masalah Ekonomi dan Pembangunan, 12(1), 102117. https://doi.org/10.23917/jep.v12i1.209 Usop, S. R. (2012). Pembangunan Berbasis MasyarakatModelPemberdayaanMasyarakat Melalui Corporate Social Responsibility. JISPAR, 1(1). Diakses dari https://e-journal. upr.ac.id/index.php/JISPAR/article/view/341 Yin, J., \& Zhang, Y. (2012). Institutional dynamics and corporate social responsibility (CSR) in an emerging country context: Evidence from China. Journal of business ethics, 111(2), 301-316. https:// doi.org/10.1007/s 10551-012-1243-4 